\title{
Commentary: At the heart of the matter-Left atrial volume index in chronic mitral regurgitation
}

\author{
Madeline L. Fryer, MMSc, ${ }^{a}$ and Leora B. Balsam, MD $^{\mathrm{b}}$
}

\author{
From the ${ }^{\mathrm{a} U n i v e r s i t y ~ o f ~ M a s s a c h u s e t t s ~ S c h o o l ~ o f ~ M e d i c i n e, ~ W o r c e s t e r, ~ M a s s ; ~ a n d ~}{ }^{\mathrm{b}}$ Division of Cardiac Surgery, \\ UMass Memorial Medical Center, Worcester, Mass. \\ Disclosures: Authors have nothing to disclose with regard to commercial support. \\ Received for publication Aug 21, 2019; revisions received Aug 21, 2019; accepted for publication Aug 22, 2019; \\ available ahead of print Sept 19, 2019. \\ Address for reprints: Leora B. Balsam, MD, Division of Cardiac Surgery, UMass Memorial Medical Center, \\ University Campus, 55 Lake Ave N, Worcester, MA 01655 (E-mail: leora.balsam@umassmemorial.org). \\ J Thorac Cardiovasc Surg 2020;160:673-4 \\ $0022-5223 / \$ 36.00$ \\ Copyright (c) 2019 by The American Association for Thoracic Surgery \\ https://doi.org/10.1016/j.jtcvs.2019.08.059
}

Mitral regurgitation (MR) is a prevalent valvular heart disorder that affects more than 2 million Americans. ${ }^{1}$ The role of mitral valve repair in patients with degenerative mitral valve disease and symptomatic severe MR is wellestablished. For patients with asymptomatic severe MR, additional clinical factors are considered when weighing the potential benefit of early mitral valve surgery. The American College of Cardiology and American Heart Association guidelines for timing of surgical intervention for severe MR in degenerative disease are based on left ventricular dilation and left ventricular ejection fraction, as well as on patient symptoms. ${ }^{2}$ The European Society of Cardiology and European Association for Cardiothoracic Surgery also include elevated left atrial volume index (LAVI) as a class IIa indication for mitral valve repair in symptom-free patients with severe MR. ${ }^{3}$

In this issue of the Journal, Balachandran and colleagues ${ }^{4}$ at the Mayo Clinic evaluate the relationship between left atrial size and outcomes after mitral valve repair for degenerative disease. Left atrial dilation is typical in patients with severe MR and occurs secondary to volume overload. With time, left atrial volume overload results in structural changes in the atrium, including fibrosis, and can lead to atrial dysrhythmias. Quantifying this process of left atrial remodeling has not been easily accomplished in the clinical setting, and there is a need for standardized methodology for doing so. In their article, Balachandran and colleagues ${ }^{4}$ evaluate the usefulness of the preoperative echocardiographic LAVI for predicting left atrial reverse remodeling and outcomes after mitral valve repair.

The study is a retrospective analysis of 720 patients undergoing isolated mitral valve repair for degenerative MR at their center. The relationships between preoperative LAVI and postrepair LAVI, postoperative atrial fibrillation, and late mortality were examined. The median preoperative LAVI was significantly greater than the upper limit of normal $\left(54 \mathrm{~mL} / \mathrm{m}^{2}\right.$ vs $\left.34 \mathrm{~mL} / \mathrm{m}^{2}\right)$, and reverse remodeling to nearly normal levels occurred within the first few

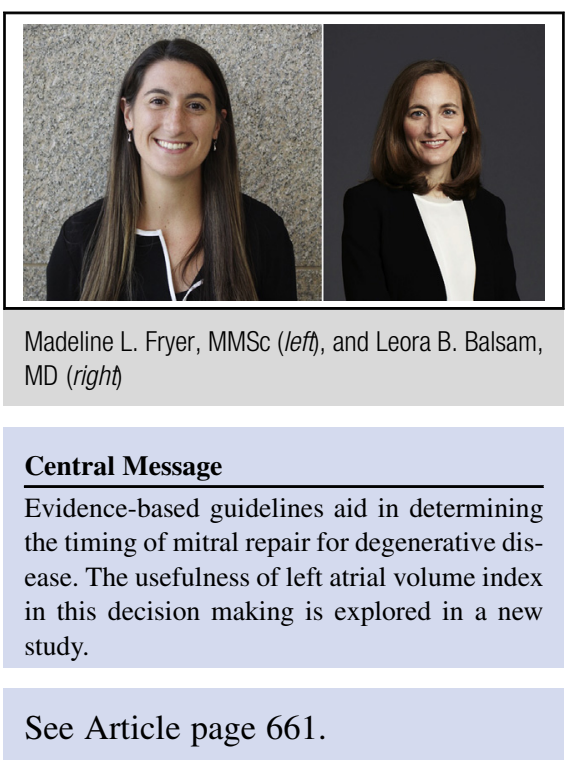

months after surgery in most cases. The extent of reverse remodeling was greatest in patients with higher preoperative LAVI; however, these patients continued to have larger LAVI postoperatively than patients with smaller preoperative LAVI. Factors that negatively affected left atrial reverse remodeling included older age, preoperative atrial fibrillation, and extremes of body mass index. Balachandran and colleagues ${ }^{4}$ found that larger prerepair LAVI was associated with higher risk of atrial fibrillation within 30 days after surgery. Increased preoperative LAVI also trended toward but failed to reach significance in association with late mortality $(P=.077)$. These findings add to previous data from Di Gioia and colleagues ${ }^{5}$ that suggest that LAVI be considered in determining timing of surgical intervention, risk stratification, and candidates for antiarrhythmic therapy for mitral valve repair and replacement patients.

Because of the exclusion of patients undergoing concomitant maze procedures, only $3 \%$ of patients in the study of Balachandran and colleagues ${ }^{4}$ had preoperative atrial fibrillation. This resulted in underrepresentation of patients with preexisting atrial fibrillation, who constitute a significant percentage of patients who undergo mitral valve repair. Taken together with evidence from experimental findings that MR-associated atrial fibrillation is the result of chronic, not acute, $\mathrm{MR},{ }^{6,7}$ it might be inferred that the patients included in the analysis of Balachandran and colleagues ${ }^{4}$ had a shorter than average duration of MR before surgical 
repair. Although data from this study contribute to the notion that LAVI may be a useful metric for predicting reverse left atrial remodeling and risk of atrial fibrillation after mitral valve repair, it is prudent to keep in mind that the chronicity of MR is likely to play an important yet unquantified role in these outcomes.

\section{References}

1. Nishimura RA, Vahanian A, Eleid MF, Mack MJ. Mitral valve disease-current management and future challenges. Lancet. 2016;387:1324-34.

2. Nishimura RA, Otto CM, Bonow RO, Carabello BA, Erwin JP III, Fleisher LA, et al. 2017 AHA/ACC focused update of the 2014 AHA/ACC guideline for the management of patients with valvular heart disease: a report of the American College of Cardiology/American Heart Association Task Force on Clinical Practice Guidelines. Circulation. 2017;135:e1159-95.
3. Baumgartner H, Falk V, Bax JJ, De Bonis M, Hamm C, Holm PJ, et al; ESC Scientific Document Group. 2017 ESC/EACTS guidelines for the management of valvular heart disease. Eur Heart J. 2017;38:2739-91.

4. Balachandran P, Schaff HV, Lahr BD, Nguyen A, Daly RC, Maltais S, et al. Preoperative left atrial volume index is associated with postoperative outcomes in mitral valve repair for chronic mitral regurgitation. J Thorac Cardiovasc Surg. 2020;160:661-72.e5.

5. Di Gioia G, Mega S, Nenna A, Campanale CM, Colaiori I, Scordino D, et al. Should pre-operative left atrial volume receive more consideration in patients with degenerative mitral valve disease undergoing mitral valve surgery? Int J Cardiol. 2017;227:106-13.

6. Ruaengsri C, Schill MR, Lancaster TS, Khiabani AJ, Manghelli JL, Carter DI, et al. The hemodynamic and atrial electrophysiologic consequences of chronic left atrial volume overload in a controllable canine model. J Thorac Cardiovasc Surg. 2018;156:1871-9.e1.

7. Lawrance CP, Henn MC, Miller JR, Kopek MA, Zhang AJ, Schuessler RB, et al. The electrophysiologic effects of acute mitral regurgitation in a canine model. Ann Thorac Surg. 2017;103:1277-84. 